\title{
ISOLASI PEKTIN DARI KULIT BUAH NAGA (Hylocereus polyrhizus) DAN PEMANFAATANNYA SEBAGAI PENGIKAT PADA SEDIAAN PASTA GIGI
}

\author{
PECTIN ISOLATION OF DRAGON FRUIT (Hylocereus \\ polyrhizus) AND UTILIZATION AS A BINDER ON TOOTHPASTE
}

\author{
Kori Yati*, Vera Ladeska, Adia Putra Wirman \\ Fakultas Farmasi dan Sains, Universitas Muhammadiyah Prof. DR. HAMKA \\ *Penulis Korespondensi, e-mail: koriyati@uhamka.ac.id
}

\begin{abstract}
ABSTRAK
Buah naga selain dikonsumsi dalam bentuk segar juga diolah menjadi beberapa produk olahan. Kulit buah naga mengandung pektin $\pm 10,8 \%$. Pada industri farmasi dan makanan, pektin digunakan sebagai pengikat, pembentuk gel, penstabil, dan pengental. Penelitian ini bertujuan untuk mengisolasi pektin, mengkarakterisasi pektin dan mengetahui pengaruh perbedaan konsentrasi pektin sebagai bahan pengikat terhadap viskositas yang dihasilkan pada sediaan pasta gigi. Pektin yang dihasilkan dianalisa secara kualitatif menggunakan FTIR dan memenuhi persyaratan JEFCA ( Joint Expert Committee for Food Additives (FAO/WHO)) dengan nilai susut pengeringan 11,03\%, kadar abu 0,41\%, berat ekivalen 617,29 mg dan kadar metoksi 6,50\%. Pektin yang sudah dikarakterisasi dibuat pasta gigi dalam 4 formula dengan konsentrasi pektin sebesar 3\%, 3,5\%, 4\% dan 4,5\%, kemudian dievaluasi sifat fisiknya meliputi organoleptis, homogenitas, $\mathrm{pH}$, viskositas dan sifat alir. Dari hasil penelitian menunjukkan bahwa semakin meningkat konsentrasi penggunaan pektin kulit buah naga maka semakin besar pula viskositas yang dihasilkan.
\end{abstract}

Kata kunci : isolasi pektin, kulit buah naga, pengikat, pasta gigi

\begin{abstract}
Dragon fruit (Hylocereus polyrhizus) consumed in fresh form is also processed into other $p \backslash$ roducts. Dragon fruit peel contains pectin $\pm 10.8 \%$. Pectin is used as a precursor jelly and juice stabilizer. In the food and pharmaceutical industry, pectin is used as a stabilizer and thickener.The study aims to isolate pectin, characterization and know the effect of different concentrations of pectin as a gelatin precursor to the viscosity generated in the preparation of toothpaste. Pectin produced qualitatively analyzed by FTIR and meet the requirements of JEFCA (Joint Expert Committee for Food Additives (FAO/WHO)) with loss on drying 11.03\%, ash value $0.41 \%$ as total ash, equivalent weight $617.29 \mathrm{mg}$ and methoxy content $6.50 \%$. Pectin which has been characterized are made toothpaste in four formulas with pectin concentration of $3 \%$,
\end{abstract}


$3.5 \%, 4 \%$ and $4.5 \%$, then evaluated their physical properties. The results showed that the use of pectin as a binding agent concentration is directly proportional to the viscosity of the toothpaste.

Keywords: pectin isolation, dragon fruit peel, binder, toothpaste

\section{PENDAHULUAN}

Dalam bidang kesehatan terutama kesehatan mulut, masalah yang sering dihadapi adalah keluhan sakit gigi. Salah satu cara untuk menjaga kebersihan gigi dan mulut yaitu dengan menggosok gigi menggunakan pasta gigi. Sediaan pembersih gigi atau pasta gigi adalah sediaan semi padat yang efektif sebagai medium terdiri dari campuran bahan penggosok, bahan pembersih, dan bahan tambahan agar zat aktif dapat bekerja pada permukaan gigi dengan efek utama adalah membuat pembentukan gigi lebih resisten terhadap kerusakan oleh bakteri mulut tanpa merusak gigi maupun membran mukosa mulut (SNI 12-3524-1995).

Salah satu komponen penting dari pasta gigi adalah bahan pengikat yang fungsinya untuk mempertahankan bentuk sediaan semisolid sehingga stabilitasnya dapat terjaga (Lieberman, 1996). Bahan pengikat dapat berasal dari polisakarida alam seperti gom alam, tragakan, pektin, turunan poliakrilat dan karaginan.

Buah naga merah merupakan buah dari suku Cactaceae, yang mulai banyak dikonsumsi di Indonesia. Buah naga selain dikonsumsi dalam bentuk segar juga diolah menjadi beberapa produk olahan, sedangkan kulitnya yang memiliki berat 30-35\% dari berat buah belum dimanfaatkan dan hanya dibuang sebagai limbah sehingga menyebabkan pencemaran lingkungan. Kulit buah naga mengandung pektin $\pm 10,8 \%$.

Pektin adalah suatu komponen serat yang terdapat pada lapisan lamella tengah dan dinding sel primer pada tanaman. Pektin digunakan sebagai bahan pembentuk jelly dan penstabil sari buah. Pada industri farmasi dan makanan, pektin digunakan sebagai pengikat, pembentuk gel, penstabil, dan pengental. Pektin merupakan asam poligalakturonat yang mengandung metil ester. Penelitian sebelumnya (Lestari, 2015) menyebutkan pektin yang berasal dari pisang kepok yang digunakan dapat digunakan sebagai pengikat pada sediaan pasta gigi. Pada penelitian ini telah dilakukan isolasi 
pektin dari kulit buah naga dan diformulasikan dalam sediaan pasta gigi, untuk mengetahui karateristik pektin yang dihasilkan dan pengaruh penggunaannya sebagai bahan pengikat terhadap viskositas sediaan gel pembersih gigi yang dihasilkan.

Konsentrasi pektin berpengaruh terhadap pembentukan pasta dengan tingkat kekenyalan dan kekuatan tertentu, sehingga penggunaan pektin dapat mempengaruhi viskositas. Pada penelitian ini, pektin diisolasi dan digunakan sebagai pengikat pada konsentrasi yang berbeda-beda. Tujuan penelitian ini adalah untuk mengetahui pengaruh perbedaan konsentrasi penggunaan pektin pengikat terhadap viskositas pasta gigi yang dihasilkan.

\section{METODE PENELITIAN}

Alat

Alat-alat yang digunakan dalam penelitian ini meliputi: blender, oven, hot plate, magnetic strirer, rotary evaporator, statif dan klem, kertas saring, furnace, desikator, multimix, pH meter (Hanna), viskometer Brookfield, homogenizer, timbangan analitik (OHaus) dan alat-alat gelas lainnya.

Bahan

Buah naga merah (Hylocereus polyrhizus) segar diperoleh dari perkebunan Purwakarta pada bulan April 2016. Bahan-bahan pereaksi (pro analisis) $\mathrm{HCl} 1 \mathrm{~N}$, etanol, $\mathrm{AgNO}_{3}, \mathrm{NaCl}$, phenolphthalein, $\mathrm{NaOH}$. Bahan-bahan lain seperti kalsium karbonat, nipagin, nipasol, gliserin, natrium sakarin, natrium lauril sulfat dan akuades (derajat farmasetika).

Jalannya Penelitian

Ekstraksi pektin dari kulit buat naga merah (Hylocereus polyrhizus)

Kulit buah naga merah yang akan diekstraksi diperoleh dari buah naga yang didapat dari perkebunan desa Pangkalan, Kecamatan Bojong, Kabupaten Purwakarta. Buah naga dideterminasi terlebih dahulu di Herbarium Bogorriense-LIPI Cibinong. Kulit buah naga merah dipotong-potong kecil dan dikeringkan dengan menggunakan 
oven pada suhu $55^{\circ} \mathrm{C}$ selama 48 jam (Tang, 2011). Setelah kulit buah naga kering diblender dan ditimbang. Sebanyak 100 gram kulit buah naga merah yang telah diblender, diekstraksi pektinnya dengan cara menambahkan akuades dengan perbandingan (1:15) dan ditambahkan $\mathrm{HCl}$ 0,1 $\mathrm{M}$ hingga $\mathrm{pH}$ 3,5. Campuran dipanaskan pada suhu $60^{\circ} \mathrm{C}$ disertai pengadukan menggunakan stirer selama 30 menit, selanjutnya disaring dan diambil filtratnya (Mokhtar, 2013). Filtrat didinginkan kemudian dilakukan pengendapan pektin dengan menambahkan etanol (95\%) dengan rasio perbandingan filtrat dengan etanol $(0,5: 1,0)$. Proses pengendapan ini dilakukan selama 6 jam (Mokhtar, 2013). Endapan pektin yang diperoleh dicuci menggunakan etanol (45\%) untuk memisahkan monosakarida dan disakarida (Mokhtar, 2013). Pengeringan pektin dilakukan terhadap pektin basah hasil cucian dalam oven pada suhu $40^{\circ} \mathrm{C}$ selama 24 jam (Mokhtar, 2013). Pektin yang didapat selanjutnya diidentifikasi dan dikarakterisasi berdasarkan Farmakope Edisi V.

Formulasi sediaan pasta gigi

Gel pembersih dibuat dalam 4 formula, dengan variasi konsentrasi pektin yang berbeda. Formula selengkapnya dapat dilihat pada Tabel I (SNI., 2015).

Tabel I. Formula pasta gigi

\begin{tabular}{|c|c|c|c|c|c|}
\hline \multirow{2}{*}{ Bahan } & \multicolumn{4}{|c|}{ Formula (\%) } & \multirow{2}{*}{ Fungsi } \\
\hline & $\mathbf{I}$ & II & III & IV & \\
\hline Kalsium karbonat & 50 & 50 & 50 & 50 & Abrasive \\
\hline Pektin kulit buah naga & 3 & 3,5 & 4 & 4,5 & Pengikat \\
\hline Nipagin & 0,18 & 0,18 & 0,18 & 0,18 & Pengawet \\
\hline Nipasol & 0,02 & 0,02 & 0,02 & 0,02 & Pengawet \\
\hline Gliserin & 25 & 25 & 25 & 25 & Humektan \\
\hline Na- Sakarin & 0,20 & 0,20 & 0,20 & 0,20 & Pemanis \\
\hline Natrium lauril sulfat & 2 & 2 & 2 & 2 & Surfaktan \\
\hline Minyak permen & 0,5 & 0,5 & 0,5 & 0,5 & Pengaroma \\
\hline Akuades sampai dengan & 100 & 100 & 100 & 100 & Pelarut \\
\hline FI $\quad:$ Pektin 3\% & & & & & \\
\hline FII $\quad$ : Pektin 3,5 & & & & & \\
\hline FIII : Pektin $4 \%$ & & & & & \\
\hline
\end{tabular}


Pembuatan pasta gigi

Ditimbang bahan-bahan yang diperlukan pada masing-masing formula. Sakarin dilarutkan dengan akuades dalam becker glass (masa 1). Nipagin, nipasol didispersikan dengan gliserin dalam becker glass (masa 2). Pektin dicampur dengan gliserin dalam becker glass diaduk hingga homogen, ditambahkan akuades diaduk dengan kecepatan sedang, kemudian ditambahkan masa 1 dan 2, diaduk hingga homogen (masa3). Ditambahkan kalsium karbonat sedikit demi sedikit mixer hingga homogen. Ditambahkan natrium lauril sulfat yang telah dilarutkan dengan sebagian akuades, diaduk homogen dengan kecepatan rendah. Ditambahkan minyak permen, diaduk perlahan hingga homogen. Selanjutnya pasta gigi dievaluasi meliputi uji organoleptis, homogenitas, $\mathrm{pH}$, sifat alir dan viskositas.

Analisa data

Dari data viskositas yang diperoleh, dianalisis menggunakan uji Analisis Varian (ANAVA) satu arah dengan membandingkan viskositas sediaan pasta gigi terhadap konsentrasi penggunaan pektin pada masing-masing formula. Dilanjutkan dengan uji Tukey HSD untuk melihat perbedaan yang bermakna antara masing-masing formula.

\section{HASIL DAN PEMBAHASAN}

Determinasi tanaman buah naga merah

Tanaman buah naga merah yang utuh dideterminasi untuk memastikan apakah buah tersebut benar-benar Hylocereus polyrhizus Britton \& Rose. Determinasi tanaman dilakukan di Pusat Penelitian Biologi-LIPI, Bogor. Didapat tanaman jenis Hylocereus polyrhizus Britton \&Rose., dengan familia Cactaceae. Tanaman dan buah naga merah diperoleh dari Desa Pangkalan, Kecamatan Bojong, Kabupaten Purwakarta. Kulit buah naga merah diambil dari buah naga merah utuh yang ditandai kulit buah telah berubah warna dari hijau menjadi merah. 
Ekstraksi pektin kulit buah naga merah

Kulit buah naga merah dipisahkan dengan daging buahnya. Kulit buah naga merah (Hylocereus polyrhizus Britton \& Rose) dirajang seukuran dadu lalu dikeringkan dalam oven selama 48 jam dengan suhu $55^{\circ} \mathrm{C}$. Perajangan dilakukan untuk memperkecil ukuran partikel sehingga mempercepat proses pengeringan. Pengeringan dilakukan untuk menghilangkan kandungan air yang terdapat dalam kulit buah naga merah. Kulit buah naga yang sudah kering diserbuk dan diekstraksi.

Ekstraksi pektin merupakan proses pengeluaran pektin dari sel jaringan tanaman. Pengasaman dan pemanasan pada ekstraksi pektin dilakukan untuk menghidrolisis protopektin menjadi pektin. Ekstraksi ini dapat dilakukan dengan asam mineral seperti asam klorida atau asam sulfat. Makin tinggi suhu ekstraksi, makin singkat waktu yang dibutuhkan untuk mendapatkan hasil yang maksimum. Pemanasan pada suhu $55^{\circ} \mathrm{C}$ bertujuan untuk mempercepat difusi pelarut ke dalam jaringan tanaman dan dapat meningkatkan aktivitas pelarut dalam menghidrolisis pektin. Ekstraksi pektin menghasilkan rendemen 15,25\%. Rincian data ekstraksi tersaji pada Tabel II.

Tabel II. Hasil ekstraksi pektin kulit buah naga merah

\begin{tabular}{lc}
\hline \multicolumn{1}{c}{ Tahapan preparasi ekstraksi } & Berat \\
\hline Buah naga merah utuh & $\pm 60 \mathrm{~kg}$ \\
Kulit buah naga merah segar & $\pm 35 \mathrm{~kg}$ \\
Kulit buah naga merah kering & $2,2 \mathrm{~kg}$ \\
Serbuk kulit buah naga merah & $2 \mathrm{~kg}$ \\
$\begin{array}{l}\text { Serbuk kulit buah naga merah yang di } \\
\text { ekstraksi } \\
\text { Pektin kulit buah naga merah }\end{array}$ & 100 gram \\
\hline
\end{tabular}

Proses pengendapan yang dilakukan bertujuan untuk memisahkan pektin dari larutannya. Pengendapan biasanya dilakukan dengan cara salting out, spray drying, dan dengan penambahan bahan pelarut organik seperti alkohol dan aseton. Penambahan etanol $95 \%$ bertujuan untuk meningkatkan banyaknya gugus karboksil yang 
teresterifikasi. Semakin banyak gugus karboksil yang teresterifikasi maka akan membuat suatu pektin tersebut mudah untuk dibuat menjadi gel.

Proses pencucian dimaksudkan agar pektin yang didapat bebas dari senyawasenyawa lain. Pengeringan pada suhu $40^{\circ} \mathrm{C}$ bertujuan untuk menguapkan pelarut yang masih berada dalam endapan dan lamanya waktu disesuaikan sampai dengan didapatkan pektin yang kering.

Pemeriksaan mutu dan identifikasi

Pada pengujian organoleptis pektin kulit buah naga merah, diperoleh hasil bau, warna, dan rasa yang sudah memenuhi persyaratan yang tercantum dalam Farmakope Indonesia Edisi IV seperti terlihat pada Tabel III.

Tabel III. Organoleptis pektin kulit buah naga merah

\begin{tabular}{lll}
\hline \multicolumn{1}{c}{ Organoleptis } & \multicolumn{1}{c}{ Hasil } & \multicolumn{1}{c}{ Persyaratan FI IV } \\
\hline Bau & Tidak berbau & Tidak berbau \\
Warna & Kuning kecoklatan & Putih kekuningan,Kuning kecoklatan \\
Rasa & Rasa mucilage & Rasa mucilage \\
\hline
\end{tabular}

Pektin yang diperoleh selanjutnya dikarakterisasi mutunya. Karakterisasi dan identifikasi berdasarkan pada FI V. Identifikasi ini dilakukan untuk mengetahui kemurnian dari pektin. Hasil identifikasi dapat dilihat pada Tabel IV.

Analisa kualitatif dan karakteristik pektin

Analisa kualitatif pektin menggunakan FTIR untuk mengidentifikasi kelompok gugus fungsional utama dalam pektin. Hasil spektrum IR pektin dari kulit buah naga dibandingkan dengan spektrum baku /standar pektin seperti Gambar 1 dan Tabel V. 
Tabel IV. Hasil identifikasi pektin kulit buah naga merah

\begin{tabular}{|c|c|c|}
\hline Metode Identifikasi & Hasil & Persyaratan FI V \\
\hline $\begin{array}{l}\text { Pektin 1g dipanaskan dengan } 9 \mathrm{~mL} \text { air } \\
\text { di atas tangas uap hingga terbentuk } \\
\text { larutan, air yang hilang karena } \\
\text { penguapan diganti }\end{array}$ & $\begin{array}{l}\text { Terbentuk gel yang kaku } \\
\text { pada pendinginan }\end{array}$ & $\begin{array}{l}\text { Terbentuk gel yang } \\
\text { kaku pada pendinginan }\end{array}$ \\
\hline $\begin{array}{l}\text { Larutan pektin ditambahkan etanol } \\
\text { dengan volume sama }\end{array}$ & $\begin{array}{l}\text { Terbentuk } \\
\text { bening }\end{array}$ & $\begin{array}{l}\text { Terbentuk endapan } \\
\text { bening, seperti gelatin }\end{array}$ \\
\hline $\begin{array}{l}\text { Larutan pectin } 5 \mathrm{~mL} \text { ditambahkan } 1 \\
\text { mL natrium hidroksida } 2 \mathrm{~N} \text {, dibiarkan } \\
\text { pada suhu kamar selama } 15 \text { menit }\end{array}$ & Terbentuk semi gel & $\begin{array}{l}\text { Terbentuk } \\
\text { semi gel }\end{array}$ \\
\hline $\begin{array}{l}\text { gel dari pengujian terdahulu ditambah } \\
\text { asam klorida } 3 \mathrm{~N} \text { lalu dikocok }\end{array}$ & $\begin{array}{l}\text { Terbentuk gel tidak } \\
\text { berwarna,dan bergumpal } \\
\text { bila didihkan }\end{array}$ & $\begin{array}{lrr}\text { Terbentuk } & \text { endapan } \\
\text { seperti gel } & \text { tidak } \\
\text { bewarna, ruah } & \text { dan } \\
\text { bergumpal } & & \text { bila } \\
\text { didihkan } & & \\
\end{array}$ \\
\hline
\end{tabular}

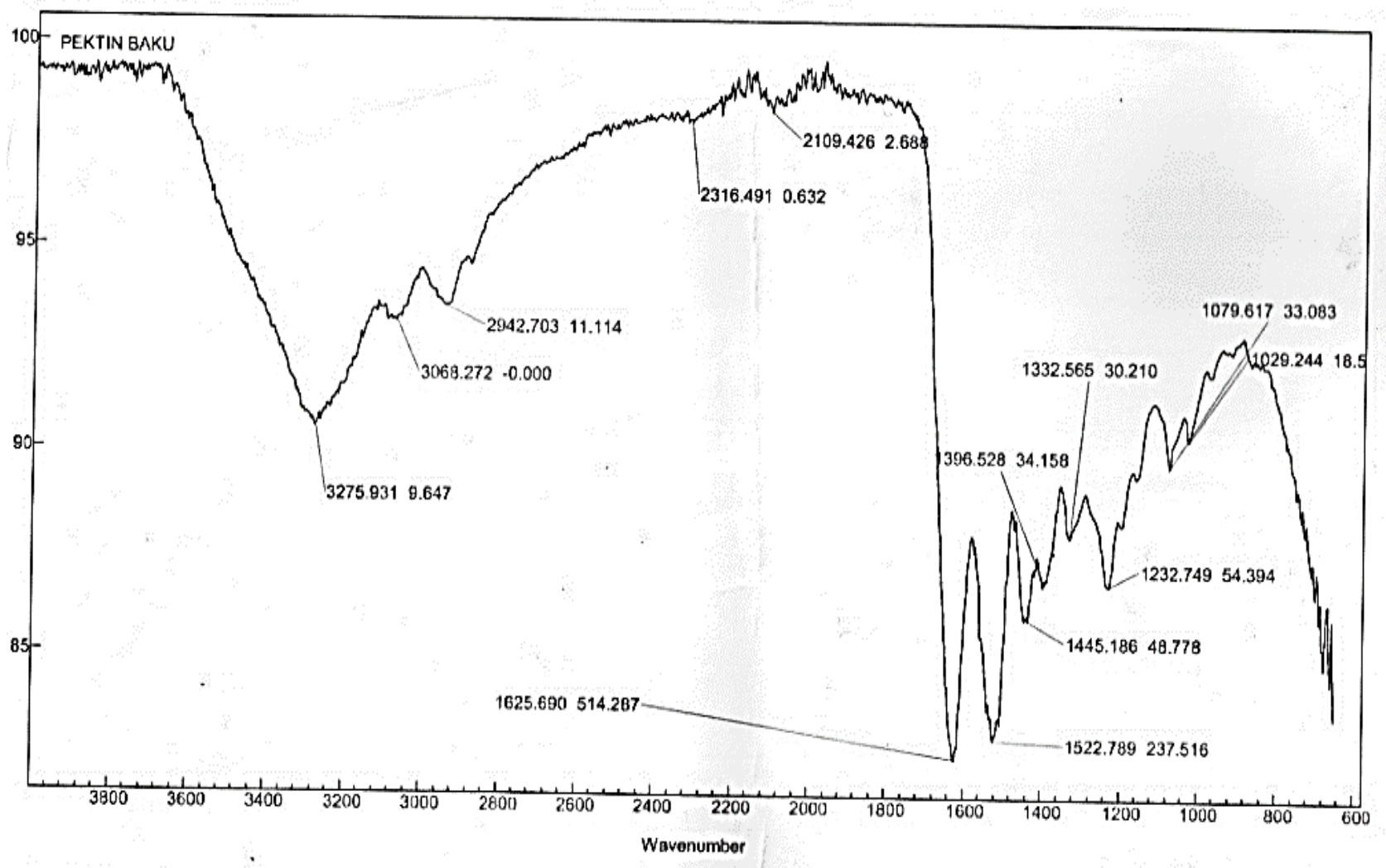

Gambar 1. Hasil spektrum IR pektin baku 
Tabel V. Hasil pembacaan spektrum pektin baku

\begin{tabular}{|c|c|c|c|c|}
\hline Gugus & Jenis Senyawa & $\begin{array}{l}\text { Daerah } \\
\text { Serapan }\end{array}$ & $\begin{array}{l}\text { Hasil } \\
\text { Serapan } \\
\left(\mathrm{cm}^{-1}\right)\end{array}$ & Keterangan \\
\hline $\mathrm{C}=\mathrm{O}$ & $\begin{array}{l}\text { Aldehid, keton, } \\
\text { asam karboksilat, } \\
\text { ester }\end{array}$ & $1690-1760$ & 695 & Tajam \\
\hline $\mathrm{C}=\mathrm{C}$ & Aromatik & $1500-1600$ & $522^{1}$ & Tajam \\
\hline $\mathrm{C}-\mathrm{O}$ & $\begin{array}{l}\text { Alkohol, Ester,Eter, } \\
\text { Asam Karboksilat, }\end{array}$ & $1080-1300$ & $\begin{array}{ll} & 1 \\
140 & \\
& 1 \\
232 & \end{array}$ & Tajam \\
\hline
\end{tabular}

Tabel VI. Hasil pembacaan spektrum pektin kulit buah naga merah

\begin{tabular}{|c|c|c|c|c|}
\hline Gugus & Jenis Senyawa & $\begin{array}{l}\text { Daerah } \\
\text { Serapan }\end{array}$ & $\begin{array}{l}\text { Hasil } \\
\text { Serapan } \\
\left(\mathrm{cm}^{-1}\right) \\
\end{array}$ & Keterangan \\
\hline $\mathrm{C}=\mathrm{O}$ & $\begin{array}{l}\text { Aldehid, keton, asam } \\
\text { karboksilat, ester }\end{array}$ & $1690-1760$ & 1741 & Tajam \\
\hline $\mathrm{C}=\mathrm{C}$ & Aromatik & $1500-1600$ & 1597 & Tajam \\
\hline $\mathrm{C}-\mathrm{O}$ & $\begin{array}{l}\text { Alkohol, Ester,Eter, } \\
\text { Asam Karboksilat, }\end{array}$ & $1080-1300$ & $\begin{array}{l}1140 \\
1095\end{array}$ & Tajam \\
\hline
\end{tabular}

Pektin berada pada wilayah antara 1.000 dan $2.000 \mathrm{~cm}^{-1}$ dari spektrum FTIR (Ismail, 2012). Pada spektrum kulit buah naga merah adanya gugus karbonil pada 1741 $\mathrm{cm}^{-1}$ menunjukkan bahwa sampel tergolong sebagai pektin dan juga adanya gugus $\mathrm{C}-\mathrm{O}$ pada $1095 \mathrm{~cm}^{-1}$ dan $1143 \mathrm{~cm}^{-1}$ yang diikuti juga oleh gugus karbonil pada $1741 \mathrm{~cm}^{-1}$ menunjukkan bahwa sampel mengandung gugus ester. Ikatan absorpsi pada $1095 \mathrm{~cm}^{-}$ ${ }^{1}$ dan $1143 \mathrm{~cm}^{-1}$ berasal dari eter. Ikatan absorpsi $1597 \mathrm{C}=\mathrm{C}$ siklik dalam struktur cincin molekul pektin. Pada spektrum pektin baku, hasil serapan juga berada pada wilayah 1000 dan $2000 \mathrm{~cm}^{-1}$ (Silverstein, 2005). Perbedaan peak yang didapat tidak sama angkanya, namun masih dalam daerah serapan yang sama. Dari penelitian menunjukkan hasil pembacaan yang sama seperti terlihat pada Gambar 2 dan Tabel VI. 


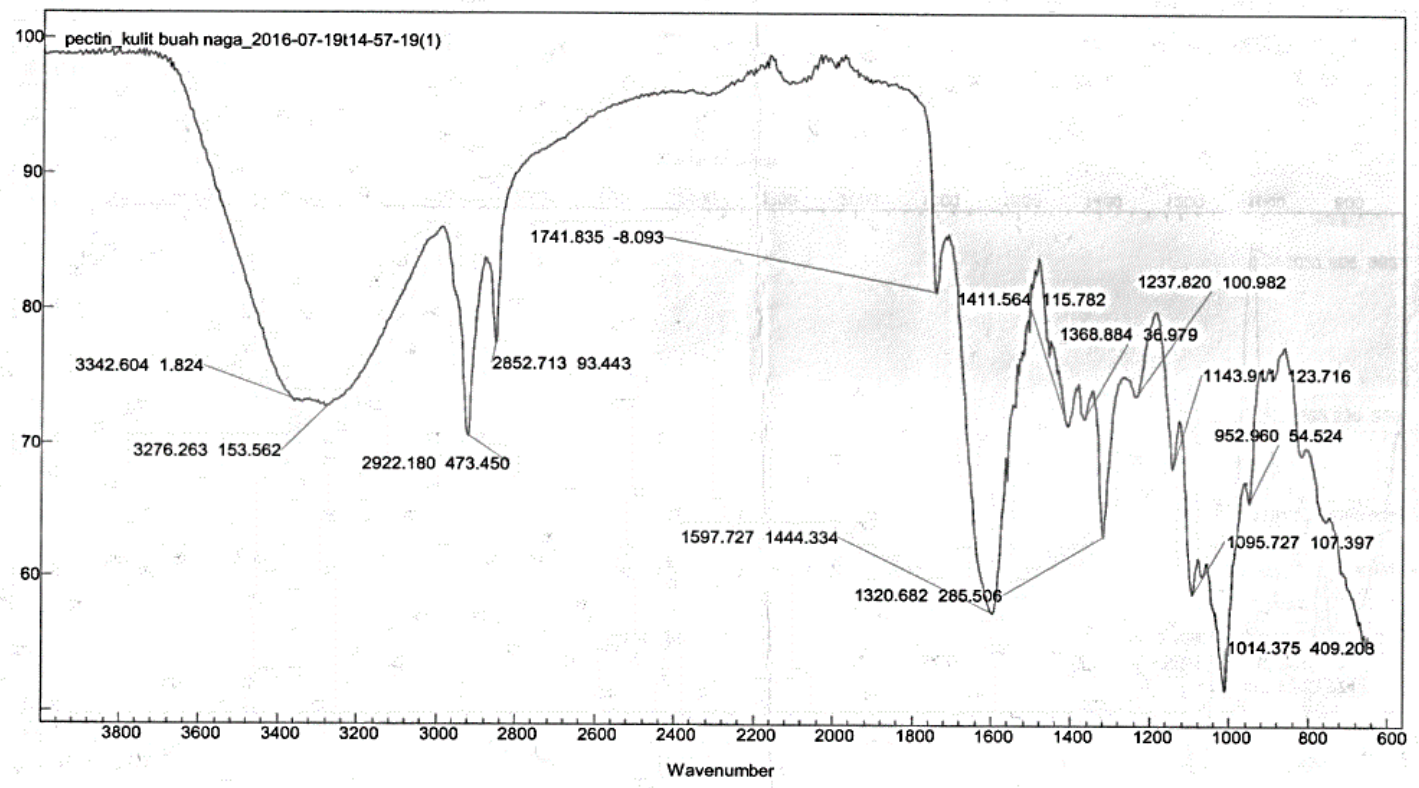

Gambar 2. Hasil spektrum IR pektin kulit buah naga merah

Hasil pengujian karakteristik pektin kulit buah naga merah meliputi susut pengeringan, kadar abu, berat ekivalen dan kadar metoksi disajikan pada Tabel VII.

Tabel VII. Hasil karakteristik pektin kulit buah naga merah

\begin{tabular}{lll}
\hline Pemeriksaan & Hasil & Persyaratan IPPA \\
\hline Susut pengeringan & $11,03 \%$ & Maksimal 12\% \\
Kadar abu & $0,42 \%$ & Maksimal 10\% \\
Berat Ekivalen & $617,2984 \mathrm{mg}$ & $600-800 \mathrm{mg}$ \\
$\begin{array}{l}\text { Kadar metoksi } \\
\quad \text { Pektin metoksi rendah }\end{array}$ & $6,50 \%$ & $2,5 \%-7,12 \%$ \\
\hline
\end{tabular}

Pada pengujian susut pengeringan, diperoleh hasil 11,03\% dan pada persyaratan susut pengeringan pektin adalah 12\%. Pengujian susut pengeringan dilakukan berhubungan dengan mutu pektin dan ketahanannya terhadap aktivitas mikroba karena senyawa lain dalam pektin termasuk air akan menguap. Pektin yang memiliki susut pengeringan di atas $12 \%$ akan mudah rusak dan tidak stabil selama penyimpanan.

Pada pengujian kadar abu diperoleh hasil yaitu $0,42 \%$, sesuai dengan persyaratan kadar abu tidak lebih dari 10\%. Pengujian ini berhubungan dengan adanya 
komponen anorganik yang tertinggal dalam pektin. Semakin rendah kadar abu menunjukkan semakin tinggi kemurnian pektin (Budiyanto, 2008).

Pada pengujian berat ekivalen pektin kulit buah naga diperoleh hasil 617,2984 mg. Berat ekivalen merupakan ukuran terhadap kandungan gugus asam galakturonat bebas yang tidak teresterifikasi. Semakin rendah kadar pektin maka kadar berat ekivalen semakin rendah. Pektin dengan berat ekivalen yang rendah akan menurunkan karakteristik gel (Ranganna, 1977).

Pada pengujian kadar metoksi pektin kulit buah naga diperoleh 6,50\% yang tergolong pektin metoksi rendah. Kadar metoksi pektin merupakan jumlah mol etanol yang terdapat dalam $100 \mathrm{~mol}$ asam galakturonat. Kadar metoksi pektin memiliki peranan penting dalam menentukan sifat fungsional larutan pektin dan dapat mempengaruhi struktur dan tekstur dari gel pektin (Constenla dan Lozano, 2003). Pektin bermetoksi rendah lebih menguntungkan dibanding pektin bermetoksi tinggi karena dapat langsung digunakan sedangkan pektin bermetoksi tinggi harus melalui demetilasi sebelum digunakan (Constenla dan Lozano, 2003).

Penentuan formula

Pada penelitian ini pektin digunakan pada konsentrasi yang berbeda-beda. Penelitian sebelumnya (Lestari, 2015) menyebutkan pektin dengan konsentrasi 2,53,5\% dapat digunakan sebagai pengikat pada sediaan pasta gigi. Pada penelitian ini dilakukan percobaan terlebih dahulu untuk mengetahui konsentrasi pektin yang akan digunakan yaitu mulai dari 1\% hingga 6\%. Pada konsentrasi 3\% hingga $5 \%$ didapat sediaan pasta gigi yang memenuhi persyaratan farmasetika, yaitu homogen atau tidak ada gumpalan partikel. Selanjutnya disusun formula pasta gigi sesuai dengan hasil percobaan pendahuluan di atas.

Karakteristik pasta gigi

Organoleptik

Dari hasil pemeriksaan organoleptis diperoleh bahwa semua sediaan pasta gigi dari formula 1 sampai formula 4 mempunyai warna putih sedikit kekuningan, berbentuk 
semi padat dan berbau khas. Sediaan memiliki warna yang sedikit kekuningan, warna ini berasal dari warna pektin yang digunakan untuk pembuatan sediaan pasta gigi. Sediaan memiliki bau yang khas karena pada pembuatan sediaan pasta gigi menggunakan bahan yang memiliki bau yang khas yaitu minyak permen.

Homogenitas pasta gigi

Pemeriksaan homogenitas diperoleh bahwa semua sediaan pasta gigi dari formula 1 sampai formula 4 homogen. Hal ini disebabkan pada proses pencampuran dan pengadukan yang tepat pada saat proses pembuatan sediaan pasta gigi.

$\mathrm{pH}$ pasta gigi

Uji keasaman dilakukan dengan menggunakan $\mathrm{pH}$ meter. Hasil pengukuran $\mathrm{pH}$ dapat dilihat pada Gambar 3.

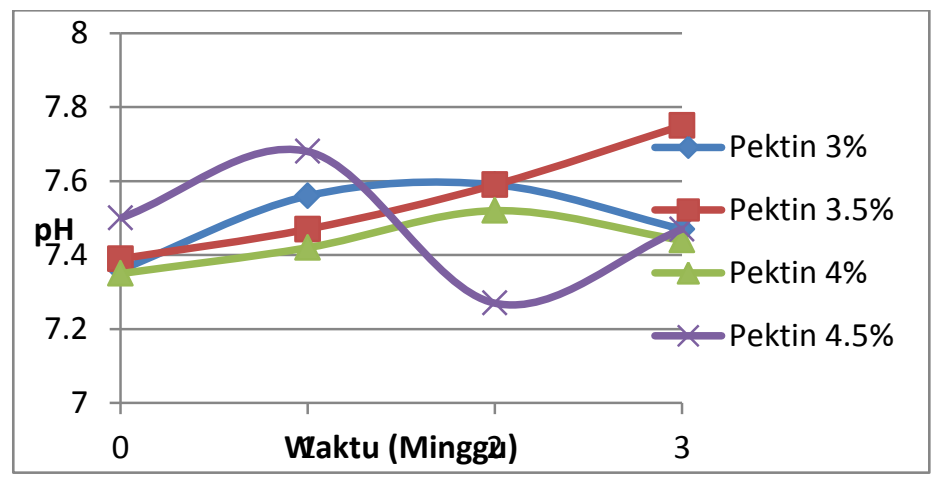

Gambar 3. Grafik pH pasta gigi terhadap waktu pada berbagai konsentrasi pektin

Dari hasil pengukuran $\mathrm{pH}$ diketahui sediaan pasta gigi yang dibuat memiliki $\mathrm{pH}$ antara 7,35-7,75. Saliva mulut memiliki pH antara 6,7-7,2 (Rieger, 2000). Apabila pasta gigi berada pada kondisi asam, maka bakteri Streptococcus mutans dapat dengan mudah berkembang dan bila pada kondisi basa, maka akan mengiritasi mukosa mulut. Hasil pengukuran $\mathrm{pH}$ di setiap formula memenuhi persyaratan Standar Nasional Indonesia yaitu 4,5-10,5. 
Viskositas dan sifat alir pasta gigi

Pengukuran sifat alir dilakukan terhadap semua formula dari formula 1 sampai formula 4 dan dilakukan dari minggu ke-0 sampai dengan minggu ke-3. Dengan menggunakan rpm 12 dan spindel nomor 7. Hasil tersebut digunakan untuk menentukan sifat alir. Penentuan sifat alir ini sangat penting dikarenakan sifat alir sediaan semi padat dapat mempengaruhi aplikasi pada tempat yang diobati dan konsistensi pengobatan (Agoes, 2012). Hasil pengukuran sediaan pasta gigi pada semua formula menunjukkan sifat alir thiksotropik pseudoplastik. Aliran thiksotropik pseudoplastik ini ditandai dengan kurva turun berada di sebelah kiri dan kurva naik berada di sebelah kanan. Ini menunjukkan adanya pemecahan struktur yang tidak terbentuk kembali jika tekanan dikurangi atau dihilangkan, akibatnya viskositas sediaan menjadi berkurang (Martin, 1990).

Pemeriksaan viskositas dan sifat alir pasta gigi dilakukan dengan menggunakan viskometer Brookfield tipe RVDV-E pada kecepatan 12 rpm dan spindel nomor 7. Hasil pengukuran viskositas dapat dilihat pada Gambar 4.

Viskositas merupakan ukuran resistensi terhadap perubahan bentuk yang disebabkan oleh fraksi internal. Oleh sebab itu, viskositas tidak boleh berubah secara drastis selama usia guna sediaan. Salah satu bentuk ketidakstabilan sistem dispersi adalah pemisahan fase. Menurut hukum Stokes bahwa dengan peningkatan viskositas akan dapat menurunkan laju sedimentasi pada sediaan (Agoes, 2012).

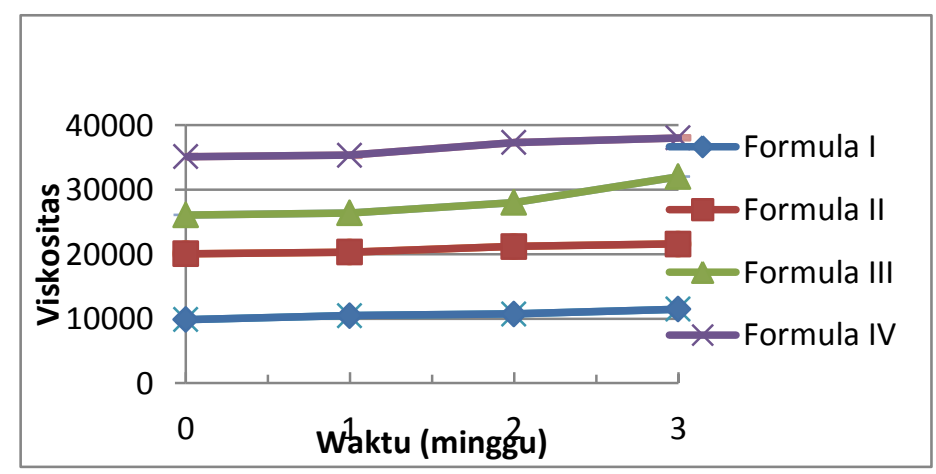

Gambar 4. Viskositas pasta gigi pada semua formula dengan pektin sebagai Pengikat 
Hasil pengukuran viskositas sediaan pasta gigi menunjukkan perbedaan viskositas pada setiap formulanya. Hal ini disebabkan karena peningkatan konsentrasi pektin kulit buah naga pada setiap formulanya. Jadi semakin tinggi konsentrasi pektin kulit buah naga maka semakin tinggi viskositasnya. Hasil uji Tukey HSD terhadap viskositas menunjukkan terdapat perbedaan yang bermakna antara masing-masing formula (antar konsentrasi pektin). Viskositas yang dihasilkan pada konsentrasi 3\% memiliki hasil yang berbeda dengan viskositas pada konsentrasi 3,5\%, 4\% dan 4,5\%, dimana sediaan pasta gigi dengan konsentrasi $4,5 \%$ memiliki viskositas tertinggi dibandingkan dengan viskositas sediaan pada konsentrasi 3\%, 3,5\% dan 4\%.

\section{KESIMPULAN}

Berdasarkan hasil penelitian dapat disimpulkan bahwa karakteristik kimia pektin hasil ekstraksi dari limbah kulit buah naga merah telah memenuhi standar mutu yang telah ditetapkan oleh International Pectin Producers Association (2002), Food Chemical Codex (1996) dan Handbook of Pharmaceutical Excipiens (2006). Formulasi sediaan pasta gigi yang mengandung pektin dari kulit buah naga, menyimpulkan peningkatan konsentrasi pektin kulit buah naga sebagai pengikat, tidak mempengaruhi organoleptis dan homogenitas sediaan, memberikan nilai $\mathrm{pH}$ yang memenuhi persyaratan dan meningkatkan nilai viskositas.

\section{DAFTAR PUSTAKA}

Agoes, G., 2012, Sediaan Farmasi Likuida-Semi Solida (SFI-7), Penerbit ITB Bandung, $176,418$.

Budiyanto A., 2008, Pengaruh Waktu dan Suhu Ekstraksi Terhadap Karakterisitik Pektin dari Ampas Jeruk Siam (Citrus nobilis L.). Dalam: Balai Besar Penelitian dan Pengembangan Pascapanen Pertanian.Bogor. 
Constenla, D. and J. E. Lozano, 2003, Kinetic Model of Pectin Demethylation, Latin American Applied Research, 33: 91-96.

Departemen Kesehatan RI, 1995, Farmakope Indonesia Edisi IV, Departemen Kesehatan RI, Jakarta.

Departemen Kesehatan RI, 2014, Farmakope Indonesia Edisi V, Departemen Kesehatan RI, Jakarta.

Ismail, N.S.M., Nazaruddin, R., Norziah, M.H, dan Zainudin, M., 2012, Extraction and Characterization of Pectin from Dragon Fruit (Hylocereus polyrhizus) using Various Extraction Conditions, Jurnal Sains Malaysiana, Malaysia.

Lestari, Pramulani Mulya dan Kori Yati, 2015, Pemanfaatan Pektin dari Kulit Buah Pisang Kepok (Musa paradisiaca) sebagai Pengikat dalam Pasta Gigi. Magra, Jurnal Lembaga Penelitian dan Pengembangan UHAMKA, Jakarta. 66-71.

Lieberman H.A., 1996, Pharmaceutical Dosage From Dispers System, Marcel Dekker Inc, New York, (I): 217.

Martin, A., James Swarbrick., Arthur Cammarata, 1990, Farmasi Fisik, Terjemahan Yoshita. UI Press.

Mokhtar, F., 2013, Synthesis and Characterization of pH Sensitive Hydrogel using Extracted Pectin from Dragon Fruit Peel. The Malaysian Journal of Analytical Science. Universiti Kebangsaan Malaysia, Malaysia.

Ranganna, S., 1977, Handbook of Analysis and Quality Controlfor Fruit Vegetable Product, Second Edition. McGraw-Hill PublishingCompany Limited. New Delhi, 35. 
Rieger, M., 2000, Harry's Cosmetology: $8^{\text {th }}$ Edition, USA.SNI 01-3524-1994. Pasta gigi. Dewan Standarisasi Nasional. Jakarta, (1):1-15.

SNI 12-3524-1995., 1995, Pasta gig, Dewan Standarisasi Nasional. Jakarta: 1-16.

Silverstein, Robert M., Webser,F.X., Kiemle, D.J., Bryce, D.L, 2005, Spectrometric Identification of Organic Compounds, $7^{\text {th }}$ Edition. John Wiley \& sons. Inc.

Tang, P.Y., 2011, Optimization of Pectin Extraction from Peel Dragon Fruit (Hylocereus polyrhizus), Asian Journal of Biological Science. Universiti Tuanku Abdul Rahman, Malaysia. 